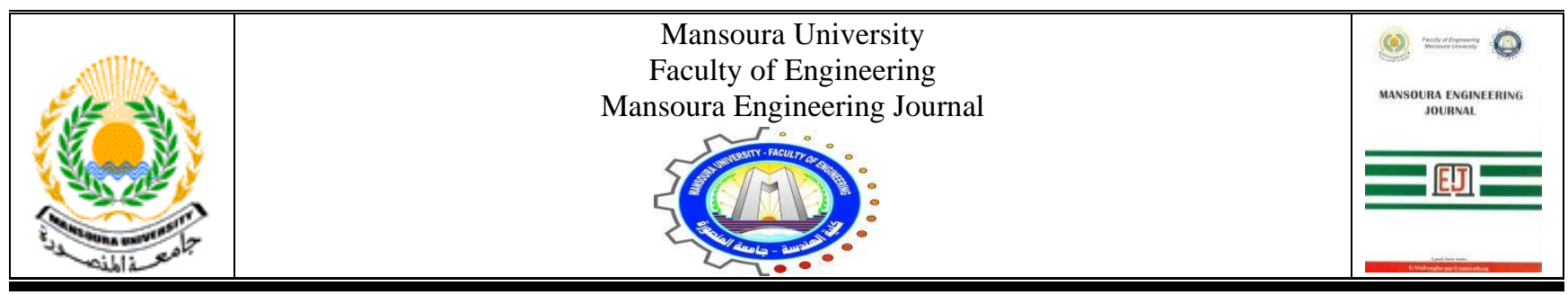

\title{
The Effect of Social Distancing on the Utilization of Open Spaces Case Study: "Open Social Spaces at Smash Academy Club"
}

\author{
Eslam N. Elsayed
}

\begin{abstract}
KEYWORDS:
Social Distancing, Physical distancing, Covid-19, open Social space, Social relation.
\end{abstract}

\footnotetext{
Abstract-Open social space is a physical space such as social center, sports club, parks or other gathering places where people gather and interact.

The aim of the research is to suggest design alternatives to deal with the negative impacts of social distancing to fulfil users' needs to perform their social activities in open social spaces during the spread of infectious viruses such as COVID-19.

The research methodology was relied on an inductive approach to acknowledge the different levels of social spaces between individuals and the real reasons why applying social distancing is difficult to verify inside social open spaces to meet individuals' needs to perform social activities. An analytical method was also applied in the study of open social space within the Smash Sports Academy to monitor the effects of implementing social distancing in the design of open social spaces.

Finally, the conclusion reached a set of results, including the cultural and economic level of individuals practicing activities inside open social spaces is correlated to their level of perception to the importance of social distancing on public health. Nevertheless, the social heritage of societies remains a key factor in the extent to which individuals perceive spaces and the manner of carrying out activities within them.
}

$\mathrm{W}$

\section{I.INTRODUCTION}

HILE urban living offers prospects of better economic opportunities and infrastructure, including healthcare facilities, the capacity of cities plays a huge rule in the spread of infectious diseases. As well as that wealth inequality in cities affects their vulnerability and capacity in terms of preparedness and response to monitor

Received: (7 October, 2020) - Revised: (31 October, 2020) - Accepted: (18 November, 2020) the spread infectious diseases.

Cities contain many open social spaces, which can be defined as outdoor spaces that are among the buildings and allow communication, transit and social interaction. Hence, social interaction by people is an essential pillar in the design of open social spaces. There are four levels of human interaction and they are intimate, personal, social and public. Social distancing ranges from a little more than a meter to just less than 4 meters, and public distancing ranges from nearly 4 to 7 meters plus. There likely will be an impact on how people

Corresponding Author: Eslam Nazmy S. Elsayed, Associate Prof. in Department of Architecture Eng., Shoubra Faculty of Eng., Benha University, Cairo, Egypt. (islam.alsayed@feng.bu.edu.eg)(amreslam@yahoo.com) 
perceive the comfort level of another person's distance from them, and how we function within this distance.

It depends also on many factors, including the cultural and social level, customs and traditions (Nassiri, N., 2010). If pandemics become annual events or permanent, personal distance might naturally become more elastic: closer during safe periods and more distant during outbreaks. The concept of comfortable personal space is one of the established rules for architects, urban designers, and planners. It is happening right now, as our sense of comfortable personal distance is being modified right in front of us (Lang,2005). We must avoid close interactions with people, to protect ourselves from epidemics such "COVID-19".

"Urban spaces are unique and must develop solutions in addition to strong disease detection and response systems to rapidly control emerging infections," said Heymann, a former executive director at the World Health Organization (WHO) (WHO, 2020). So, urbanization has been identified as one of the key challenges for public health in the 21 st century, even as it notes municipal agencies often implement health policies first and act more quickly than federal bodies in emergencies (Chandran, 2020).

\section{A. Research problem}

Social interaction within open social spaces, especially clubs, is one of the most important pillars of urban design on which the urban designer depends. Social distancing has become a lifeline that protects us from the spread of viruses.

Therefore, this research paper addresses many questions that relates to social distancing:

- The impact of COVID-19 virus the social lifestyle of Egyptians (in case of it. Will it's continuation).

- The ability to keep social activities while retaining urban social distancing.

- The specification for redesigning open social spaces.

- how does the urban designer manage to achieve both; interaction while social distancing in designing open social spaces within social clubs?

\section{B. Research aim}

To suggest design alternatives to deal with the negative impacts of social distancing to fulfil users' needs to perform their social activities in open social spaces including clubs during the spread of infectious viruses such as COVID-19.

\section{Research Methodology}

The research methodology is based on:

Inductive approach:

1. theoretical study for identifying social distancing, the main difference between social distancing and physical distancing. Also, to acknowledge the different levels of social spaces left between individuals and addressing social and urban theories to design open spaces to meet the needs of individuals while performing different activities.

2. Analytical approach:

By observation and analyzing one of the open social spaces inside Smash Sports Club (one of the sports clubs in Cairo), where the area, the urban design, and the number of individuals who are allowed to be in the space according to the social distancing distances from 1 to $2 \mathrm{~m}$. This observation will take place for 30 days across the month of July at different times of the day. Questionnaires are also analyzed for 30 members of the Smash Sports Club, to identify the degree of their satisfaction of the concept of social separation, and the extent of their willingness to practice activities among them while maintaining safe social distancing to avoid the spread of epidemics.

\section{II.THEORETICAL FRAMEWORK FOR THE STUDY}

This part deals with the definition of social distances and their different variations. What is difference between social distancing and physical distancing? As well as the concept of handling an open space is addressed; as it is essential to achieve social relations.

\section{A. Definition of social distancing.}

Social distancing means preserving a distance or space between people to help prevent the spread of the disease. To help slow the spread of viral diseases like COVID-19 and reduce the risk of infection, stay at least 6 feet (1.8 meters) away from others (Watsonville, 2019). Maintaining physical spacing is important, even if you are not sick.

\section{B. Social distancing vs. physical distancing.}

Social distancing refers to staying at least 6 feet away from people to avoid getting sick and the spread of COVID-19. Despite of using this definition widely, it may be sending the wrong massage and contributing to social segregation.

While "physical distancing" involves physically keeping yourself away from other people but stay socially connected, this helps to emphasize the importance of maintaining a physical distance between each other because it is an effective method of helping slow the spread of SARS-CoV-2, the virus that causes COVID-19. But it becomes increasingly important to maintain social and emotional contact with friends and family. Currently we need to support each other but keep the physical distance as far as possible.

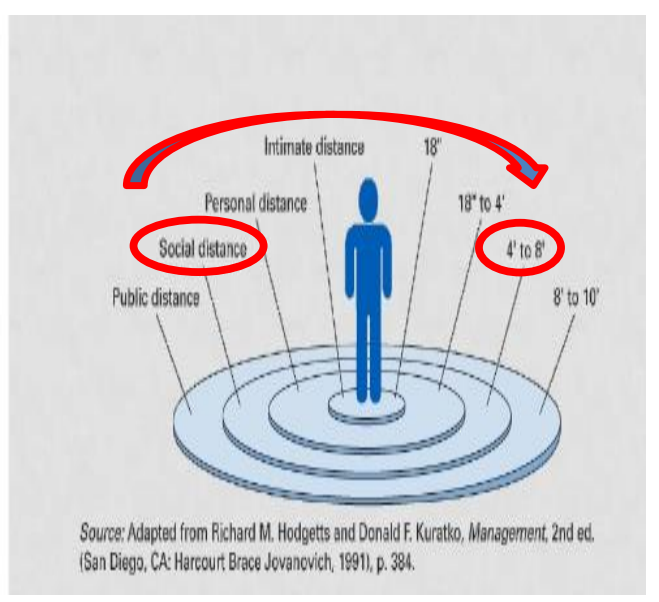

Figure.1 Personal space $\&$ Social distance Source: Richard M. Hodggetts and Donald F. Kuratto. (San Diego, CA:Harcourt Jovanovich (1991) 384. 
Additionally, World Human Organization (WHO) also preferred to use the phrase 'physical distancing' instead of 'social distancing', as the latter may imply "disconnect[ing] from our loved ones, from our family". Figure. 1

WHO recommended different levels of social distancing in countries between ( $1 \mathrm{~m}$ to $2 \mathrm{~m}$ ), which has been followed by China, Denmark, France, Hong Kong \& Singapore. India has been maintaining 2 meters' distance. However, it remains for each country to determine the safe social distancing for their population, i.e. At the most stringent level, Canada has insisted on the $2 \mathrm{~m}$ of physical distancing rule. The Boris Johnson-led UK government also opted for the $2 \mathrm{~m}$ physical distancing rule before announcing that a " $1 \mathrm{~m}$ plus" rule will begin from 4 July onward (WHO, 2020). Scientists have indicated an essential transmission factor is the time of contact. The more time you spend near an infected person, the greater the risk of transmission. As an example, they have suggested that spending six seconds within one meter of the person you are dealing with equals spending a full minute with a person you deal with at a distance of two meters. Figure. 2

\section{The Vital Importance of Social Distancing}

How a reduction in social contact can reduce

the spread of the coronavirus

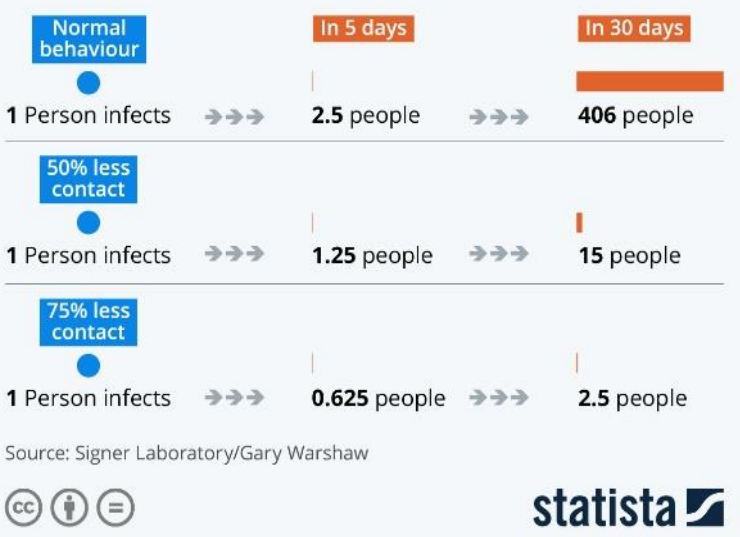

Figure. 2 How a reduction in social contact can reduce the spread of the Covid-19

Martin Armstrong, The Vital Importance of Social Distancing, Mar 23, 2020, based on calculations by Robert A. J. Signer,

Assistant Professor of Medicine at the University of California San Diego, shows how this so-called social distancing can reduce the spread of the virus.

\section{Aspects affecting the application of social distancing}

The application of social distancing to prevent the spread of the COVID-19 is one of the challenges facing the Egyptian community because Egyptian culture has various aspects that distinguishes it, including:

Social aspects: Overcrowding which is most typical for our country makes it hard to observe social distancing and avoid physical contact. People tend to congregate at cafes and smoking venues, and at crowded traditional social gatherings. Most towns have housing for the elderly, but they lack special protection or isolation measures.

Religious aspects: Most of the Egyptian population is Muslim; many, particularly the elderly, generally attend mosques for some of the five daily prayers. Attendance at mosques was only recently restricted to maintain social distancing. A similar move took place among the Christian sectors. now, public awareness is higher, but with the reopening after lockdown, it may be difficult to maintain social distancing between community members.

Cultural heritage: The challenges posed by social, religious and language norms are greatly exacerbated among the Egyptian community. For example, most weddings take place with a huge number of people, as that is a cultural norm.

Economic and cultural aspects: slum areas suffer from the lack of clean water and electricity supply. Also, the general awareness of the epidemic risks and the importance of following rules of hygiene and social distancing are fairly low.

\section{D.Definition of social public spaces}

Public spaces are a part of the ever-present vocabulary of urbanism. They are transformed through the history to enable the connectivity among community individuals.

Whereas each public space has its own spatial, historical, environmental, social, and economic features (UNHabitat,2013). This definition of public spaces strongly points out the importance of removing the profit motive in public spaces, because individuals in these open spaces differ from place to another and henceforth the concept of personal spaces also differs. Social diversity is a natural aspect of public spaces, where the social well-being of all society individuals should be equally represented. Hence, public spaces are considered an essential element of individual and social welfare (Bravo,2013). Public spaces have distinct features that cannot be found in any other spaces as they are not dedicated to personal use, so they should be accessible and socially diverse.

The Centers for Disease Control and Prevention (CDC) has flagged mental health as a top concern associated with COVID19. Therefore, we recognize that social distancing may take a toll on our mental health, especially during high-stress and anxiety producing by the COVID-19 pandemic. However, open social spaces provide a connection to the outdoors, green space and physical activity which studies demonstrate reduces stress levels and improve mental health (Watsonville, 2013). Therefore, practicing social activities in open spaces should be used in a safe manner that allows human to enjoy the mental and physical health benefits that these spaces provide.

\section{E. Transition from private zone to public zone.}

While observing towns and cities, it can be realized how daily life contradictions are found upon the differences between public and private zones (spheres) (Foucault, 1986). So, the terms public and private are clarified to show the difference in access to spaces or zones and how it is controlled (Foucault, 1983).

The term public is originally derived from the Latin word 'populus' which means 'people'. The dictionary meaning of the word 'public', is that the people constituting a community, 
state, or nation; or a collective group regarded as sharing a common cultural, social, or political interest. These meanings of the word 'public' are all referring to a large number of people who are either conceptualized as a society or as a state and have in common what is associated with them (Waite, 2009).

On the contrary, the term 'private' means a particular group of people; "not sharing thoughts and feelings with other people" (Legeby, 2010). Spaces are structured around four major categories. Figure.3

- The private sphere, which represents the individuals in the 'small' family, who live together.

- The neighbors' sphere, which people share the same entrance, staircase, courtyard or streets.

- The local publicness, that represents the interpersonal relation happens at a neighborhood level. otherwise all people are recognizable as residents, hence the mix of residents and non-residents is a salient precondition (Legeby, 2008).

- The cosmopolitan publicness, that is featured by a wide diversity of individuals or strangers.

Considering the fact that the local publicness is the most relevant sphere in which social distancing and safety precautions must take place as to contain the spread of infectious diseases such as COVID-19 and preserving the health of the community with all its different diverse groups.

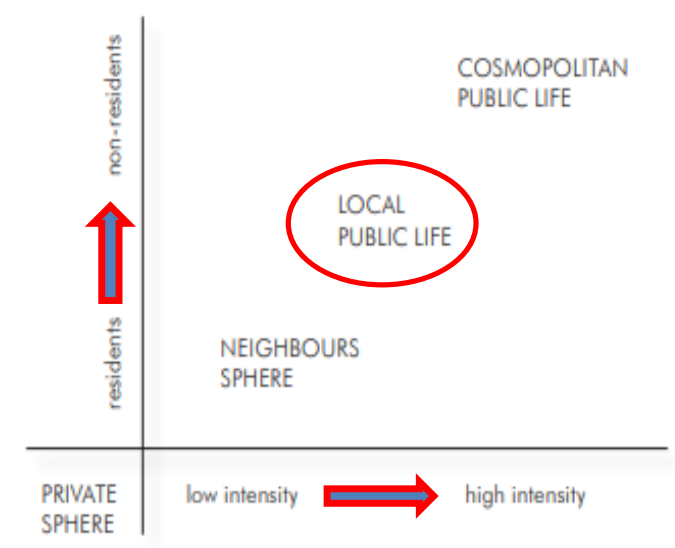

Figure. 3. Four categories of social life Source: Legeby, A. “Architectural Inquiries,"Interpretation of Olsson conception about the four categories of social life (2008) 56.

\section{F. Space Perception}

Urban designers play a key rule in shaping the environment we all live in, and this requires a thorough understanding of current needs to successfully develop open spaces. As a better understanding of what individuals or the population as a whole associate with, spatial qualities are helpful in providing the world with better buildings or spaces.

Based on Hall's (1966) theory, the interpersonal distance people choose while interacting with others depends not only on the personal attitude towards another person but also on certain characteristics, like their gender, age and the social physical environment where the interaction takes place.

Always it is attempted to relate the preferred social, personal and intimate distances observed in each country to a set of individual characteristics which are age and gender. Some variation in results can be explained by temperature in each region as well as some attributes of their cultures.

So, cultural norms are the most important factors to describe the preferred social distance. As Hall stated that what is intimate in one culture may be personal or social in another and suggested that there are specific customs regarding the spatial behavior. Hall grouped the cultures into two different classes: contact and noncontact cultures. Contact cultures use closer interpersonal distances and engage in more touching, whereas people in noncontact cultures exhibit opposite preferences and behaviors (Hall, 1966). While showing the variability of interpersonal distancing across cultures, this has clearly shown that social distancing can vary widely across countries within the same continent even though they share cultural similarities (Shuter, 1976). There are cross-cultural variations in individuals' behaviors and how they choose to distance themselves from one another. Such differences might be underpinned or linked to cultural norms, but at the same time, these norms could be associated with certain psychological and ecological variables.

There are two views that explain the perceptions about the relation between society and space. The first view sees that our socio-spatial environment is deficient since the heterogeneous urban environment does not reflect various kinds of social groupings. The second view sees that social groupings exist independently of space, not requiring spatial restructure to make them better (Hanson, 1987).

So, when designing open social spaces, we find that there is a relationship between the characteristics of the spaces and the consequent change in human behavior because of the changing human perception of these spaces. Urban designers must consider designing open social spaces to accommodate the requirements of safe social distancing that the world requires in the current period to avoid epidemics (Hiller, 2007).

\section{III.APPLIED STUDY}

The World Health Organization (WHO) has set one meter between people as minimum space for safe interaction. Some countries followed these guidelines while others preferred to choose greater distances. As for Egypt, it did not specify certain social distance between individuals in public or recreational places, it was agreed to be between 1 to $2 \mathrm{~m}$; while keeping this range as defined by physical distancing to achieve social interaction for good mental health. According to the safe social distancing between individuals 1-2 $\mathrm{m}$, which was determined by the World Health Organization (WHO). The area of the safe circle around each person becomes as follows, Figure. 4:

To achieve $1 \mathrm{~m}$ between individuals, the area of the safe social circle for everyone with a radius $(0.5 \mathrm{~m})=0.8 \mathrm{~m}^{2}$

And to achieve $2 \mathrm{~m}$ between each individual and the other, the area of the safe social circle for everyone with a radius (1m) $=3.14 \mathrm{~m}^{2}$ 
An insecure and impenetrable distance between individuals

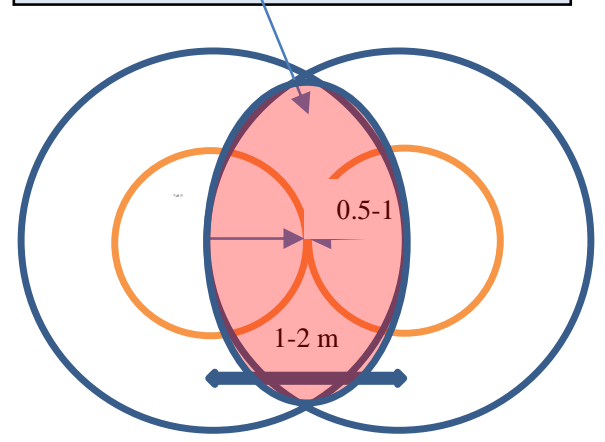

Figure. 4. Safe distancing between (1 to $2 \mathrm{~m}$ ) Source: researcher

The safest circle area around the person ranges between (.8$3.14 \mathrm{~m}^{2}$ ). The "Smash Sports Club", Cairo, Egypt was chosen as a case study to apply the above-mentioned safe areas. The reason for choosing this club as a case study model is its location in Greater Cairo; and the high economic, cultural and educational level of its members. In addition to the quality of the sport activities provided. The club has implemented a set of precautions to prevent the spread of Coronavirus (COVID-19) to ensure that the $0.5-1 \mathrm{~m}$ club members perform sports or social activities safely.

The analytical study is carried out through the current observation, interviews and questionnaire to monitor how the club has achieved social distancing in open social space and how individuals are reacting to it. The analytical study covered the following:

- Mathematical studies, to calculate the maximum number of people in open social space according to the safe circle area for each person.

- Observations, to observe the response of people to achieve safe distances at different times across 30 days throughout the month July 2020, and after the lockdown was lifted by achieving precautionary measures.

- Interviews with club members in the case of noncompliance with the safe distancing which would be noticed through observation.

- A questionnaire to indicate the following points: -The club members overall satisfaction with the social distancing measures taken inside the open social area.

-The club members acceptance of the idea of social distancing while practicing social activities.

-The members' approval/ rejection of the club procedures regarding social distancing measures followed.

- The appropriate techniques/technologies to achieve social distancing in open social spaces.

- The Smash Sporting Club is located next to Cairo Airport. It is considered a social sports club with an area of 10 acres and is currently under construction and there will be a future extension, to the west, with an area of 16 acres. The club has around 3000 memberships, including family memebers, this cause the total number of members to reach around 12000 members. Figure. 5

- The area of the main open social space is about $790 \mathrm{~m} 2$, during the case study the space was divided into four zones (A, B, C, D), in order to facilitate calculating the area and finding out the (max. / min.) number of individuals allowed to be present in each area according to safe circle area for each person $\left(0.8: 3.14 \mathrm{~m}^{2}\right.$. Figure. 6

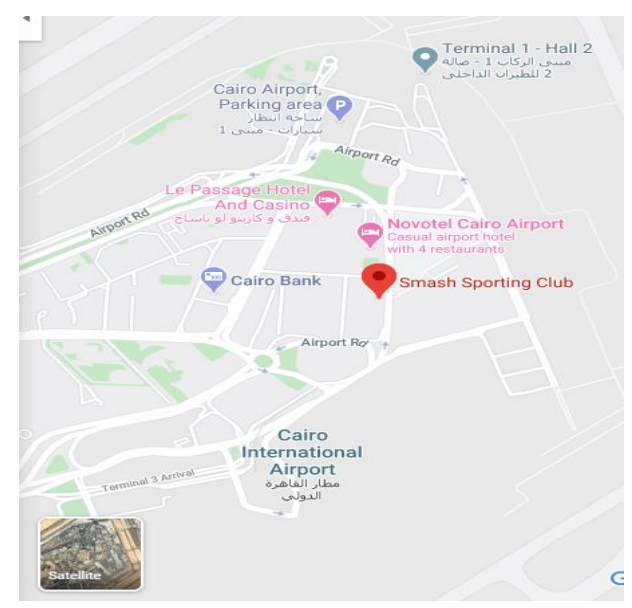

Figure. 5 The geographical location of Smash Academy location Source: researcher
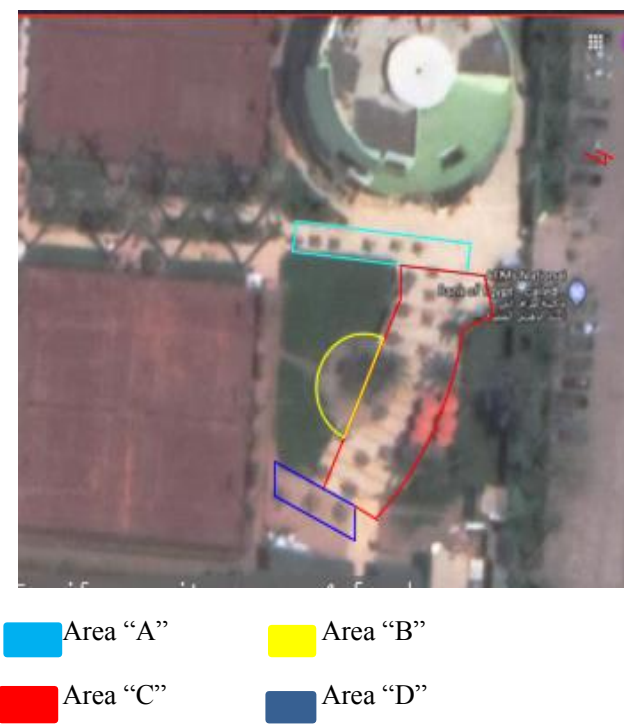

Figure.6 The division of the study area into four zones (A, B, C, D) Source: researcher

\section{A. Observation of studied areas}

By observing the open social space, it was revealed that there are several procedures that the club management has taken to redesign the space. This following is part of the measures set to accommodate the members:

- Reduce numbers of members allowed to be present at once, to achieve social distancing and thus prevent the likelihood of spread of the epidemic of COVID-19.

- Reduce the number of tables in open social spaces (from 110 to 47 tables). Figure. 7

- Increase the distances between tables to more than $2 \mathrm{~m}$.

- Limit the number of on tables to max. four seats.

- Use landscape elements such as different kinds of plants or trees and space furniture to determine areas of social activities, while maintaining social distancing. 


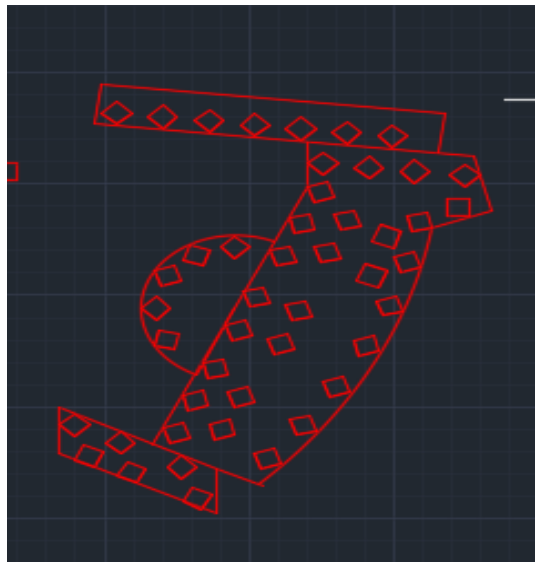

Figure.7 The method of furnishing the open social space from observation

Source: researcher

Through the study, the main open social space was divided into four zones to achieve accurate observation, and by determining the area of each zone, the minimum and maximum numbers of individuals who are allowed to be in this space were calculated according to the social distancing measurements between individuals 1 to $2 \mathrm{~m}$ (a circle of $0.8 \mathrm{~m}^{2}$ to $3.14 \mathrm{~m}^{2}$ ).

The observation was done during the month of July 2020 to notice the individual's commitment to the club rules regarding the number of seats and social distancing $(2 \mathrm{~m})$ in each zone.

The 30 days observation to the members behavior in four zones was done to reveal their commitment to the number of seats allowed by the club in each zone; in order to calculate the percentage of members who followed the club rules. Table 1

TABLE 1:

STUDY ZONES, OBSERVATION OF NUMBERS OF INDIVIDUALS IN A STUDY PERIOD.

\begin{tabular}{|c|c|c|c|c|c|c|}
\hline \multirow[b]{2}{*}{ 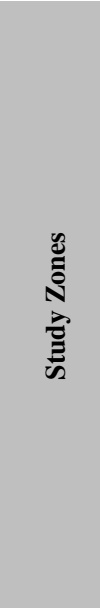 } & \multirow[b]{2}{*}{ 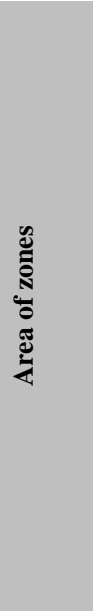 } & \multirow[b]{2}{*}{ 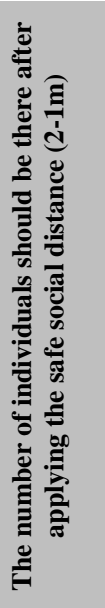 } & \multicolumn{4}{|c|}{ From Observation } \\
\hline & & & 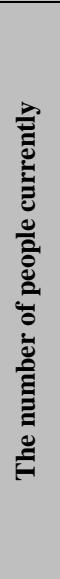 & 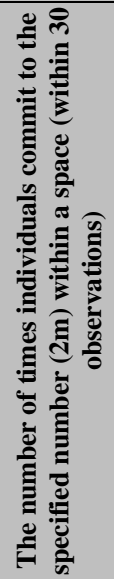 & 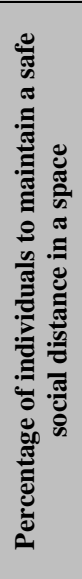 & 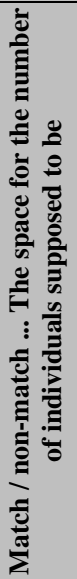 \\
\hline Zone A & $135 \mathrm{~m}^{2}$ & $169-43$ & 28 & $27 / 30$ & $90 \%$ & $(\nabla)$ \\
\hline Zone B & $85 \mathrm{~m}^{2}$ & $106-27$ & 23 & $14 / 30$ & $47 \%$ & ( \\
\hline Zone C & $500 \mathrm{~m}^{2}$ & $625-159$ & 112 & $25 / 30$ & $83 \%$ & ( \\
\hline Zone D & $70 \mathrm{~m}^{2}$ & $88-23$ & 24 & $20 / 30$ & $67 \%$ & $(2)$ \\
\hline & $790 \mathrm{~m}^{2}$ & $988-252$ & 163 & & & \\
\hline
\end{tabular}

The observation main points are: -

- Most of the observations during the month of July, showed that more than $67 \%$ followed the club rules regarding number of seats in zones (A, C, and D). As for zone (B), only $47 \%$ the club rules. And the number of individuals within each zone did not exceed the permissible amount in each area.

- Members increased the number of seats around each table more than the allowed (4 seats) for more social interactions.

It has been observed that friends of the same age group sit together without maintaining a safe social distance. They explain their behavior by saying that they will not be affected as they are young and athletic.

\section{B. Interviews with club members}

Interviews were conducted with members who did not maintain the safe distancing during observation periods (especially on the weekends and later in the day), and when asked about the reason for the gatherings without adhering to the rules of social distancing, the answers were as follows:

- They are having family gatherings because the club is the safe open place where they can gather after an absence of social interactions during the period of the lockdown that was enforced to prevent the spread of COVID-19.

- $\quad$ Friends who engage in sports activities together claim that the club is already taking social distancing precautions; in addition, that they have strong immunity as they are young and athletic.

- $\quad$ The club is already taking many precautionary measures in addition to social distancing, which makes the club a safe place that prevents the transmission of COVID-19, including:

$\checkmark$ Entering from one gate and exiting from another gate. Taking temperature measurements when arriving, and those who are not wearing masks prohibited from entering.

$\checkmark \quad$ All employees wear face masks while they are working.

$\checkmark \quad$ There are many hand sanitizing stations in different areas in the club.

$\checkmark$ Continuous sterilization of all open social spaces.

$\checkmark \quad$ Reducing the club's capacity to max. $25 \%$.

$\checkmark \quad$ The club repositioned the layout of the furniture to ensure social distancing in the open social spaces.

Despite the high cultural, social and educational level of the club's members, there have wrong belief that they would be difficult to practice their social activities while there is social distancing. It is considered a dangerous matter because the World Health Organization considered physical distancing to be the most important factor to prevent the COVID-19.

\section{Questionnaire with club members}

A questionnaire was conducted on 30 members (age 25-40, both sexes) of the club, to take their opinions on their satisfaction with achieving social distancing within open social 
spaces, by using a variety of open and closed questions.

- Are you satisfied with the procedural measures of social distancing within the open social spaces?

-The majority, which amounts to $60 \%$, agreed with the social distancing measures applied within open social spaces.

-While a percentage of $30 \%$ of the sample agreed with the procedures followed by the club, with some reservations, due to some issues including: Non-compliance by some members with the rules of social distancing (such as: increasing the number of seats on a table to more than 4) Figure.8

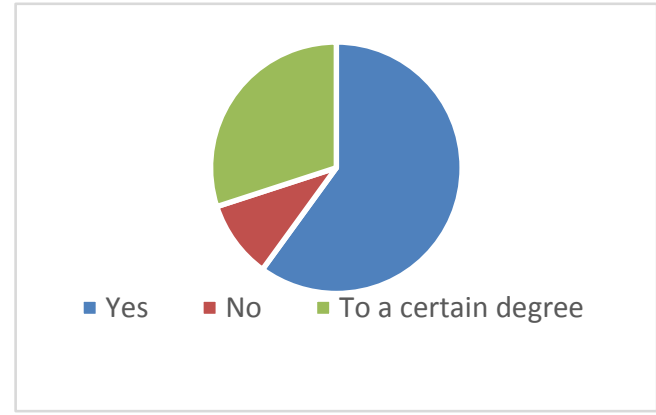

Figure. 8 People's satisfaction with procedures of social distancing followed within social open spaces. Source: researcher

- Do club members participate in social distancing measures?

$-50 \%$ of the respondents said that the club presented a range of sets of ideas and opinions on the official webpage and that the members chose a set of procedures that suited them most.

-About $40 \%$ of the sample stated that they did not agree with what the club proposed on its webpage, because the precautions followed are often the same everywhere; as the main purpose of the club is to reduce the number of individuals in the social open spaces. Figure. 9

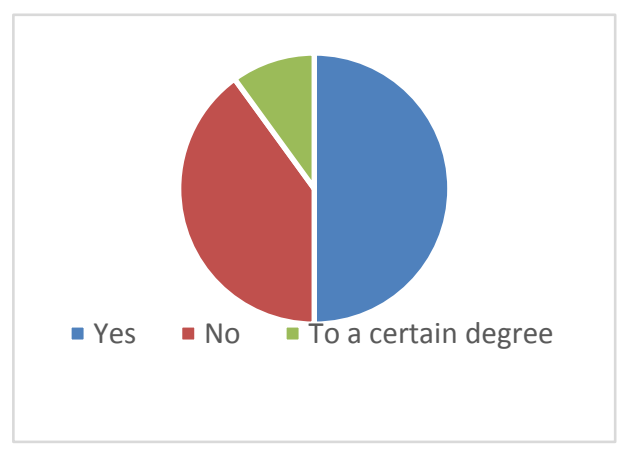

Figure. 9 Club members involve in social distancing procedures. Source: researcher

- From your point of view, what is the most effective way to achieve social distancing within open social spaces Figure.11 (more than one answer can be chosen):

- (A) Ranging between tags, no fixed anchor needed.

- (B) Ranging between tags, fixed anchor needed.

- (C) Use technological techniques (Alarm/ vibration/ light triggered when intruding $6 \mathrm{ft}(1.8 \mathrm{~m})$ social safe zone) Figure. 10

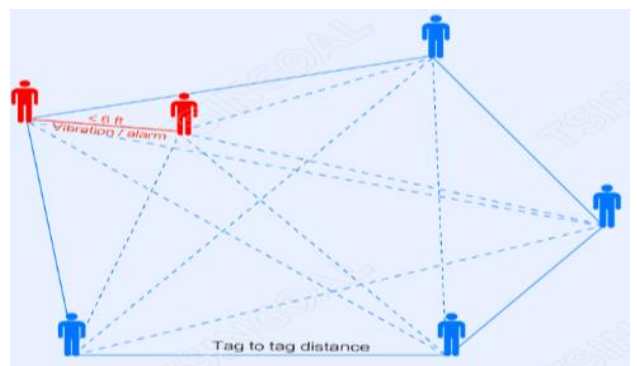

Figure. 10 Determine the points of anchor to achieve social distancing.

Source: https://theprint.in/theprint-essential/1m-1-5m-2mthe-different-levels-of-social-distancing-countries-arefollowing-amid-covid/449425/

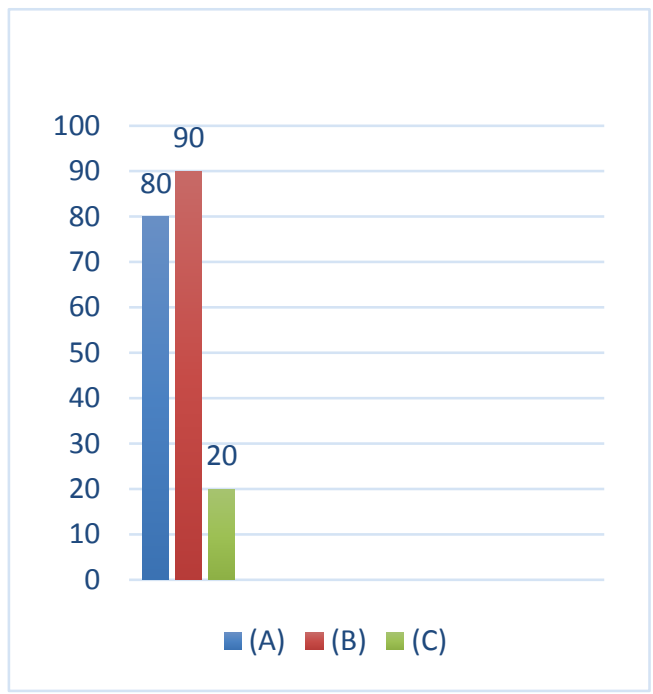

Figure. 11 The most effective way to achieve social distancing within the open spaces. Source: researcher

Despite the effective technological role in presenting many smart solutions to the problem of social distancing to prevent the spread of infectious diseases such as COVID-19; the club members (with high educational and cultural level) do not prefer any technological solutions or constrains in the open social spaces.

- From your perspective, is social distancing an effective way to prevent the spread of infectious diseases such as COVID19 inside the club.

If the answer is "no" then why? Figure. 12

Some of the responses given are as follows:

-Achieving social distancing within clubs is inconsistent with the nature of social activities inside it.

-The social heritage of the Egyptian people, who love social gatherings between family and friends makes it hard to maintain social distancing.

- Most Egyptians do not take the rules of social distancing seriously in preventing the spread of the Coronavirus. 


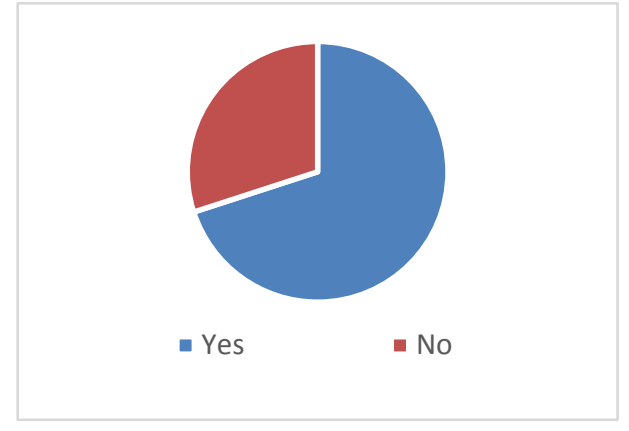

Figure.12 social distancing an effective way to prevent the spread of infectious diseases such as COVIDE-19 inside clubs. Source: researcher

- From point of view, what are appropriate solutions to redesign social open space to achieve social distancing in the time of COVID-19. Figure. 13 (more than one answer can be chosen):

-(A) Space furniture

-(B) Plants (trees/shrubs)

-(C) Water features

-(D) fences

-(E) Floor level

-(F) Technological anchors

•(G) other.......

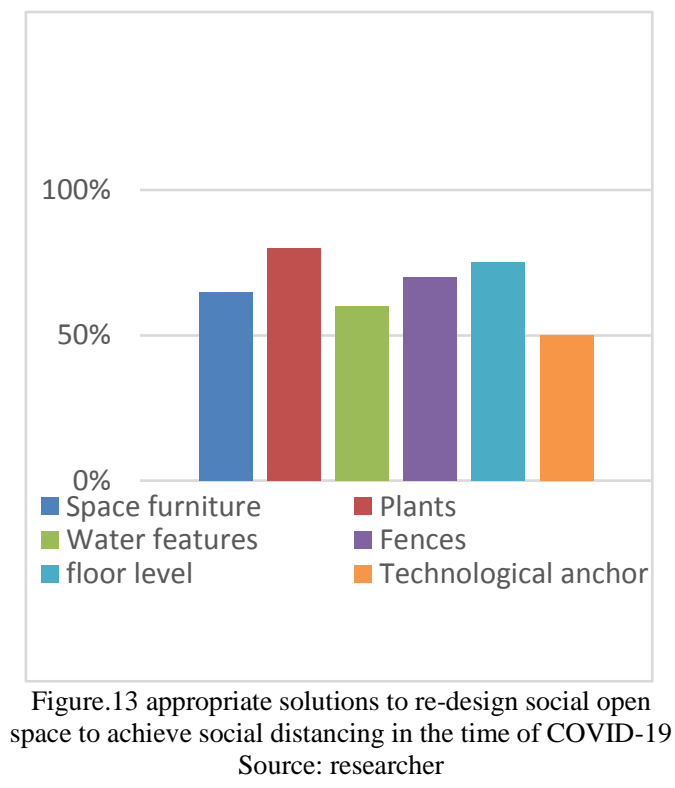

Most of answers preferred landscape features nearly with a same percentage; and some of club members suggested different ideas such as using fixed benches surrounded by trees and shrubs to permit social joyful interaction with social distancing instead of tables and seats.

\section{IV.DISCUSSIONS}

Urban designers are responsible to design open spaces with human activities in mind. According to this study, they have to redesign social open spaces to prevent the spread of epidemics, which is COVID-19. It has become imperative for the urban designers to redesign open spaces using landscape elements to achieve social distancing. Especially since some epidemics such as COVID-19 may last potentially for years, and social distancing will become part of the general pattern of performing social activities. The social safety profile is defined by the World Health Organization, but in Egypt, it is often faced by three types of human reactions:

The first: Individuals who are committed to the procedures of separation within open social approved by (WHO).

The second: The group that rejects any of the measures of social distancing due to cultural, social and economic patterns that differ from one society to another.

The third: Individuals whom are convinced that open social spaces are considered the basis for practicing social activities without any forced restrictions. Those individuals make changes to the open spaces on their own to allow them to practice social activities comfortably due to their social cultural communities

Although Smash Sports Club is considered of high social and economic class, it has been observed that some members do not adhere to social distancing rules to allow them to engage in social activity without the presence of negative effects resulting from restrictions on space distancing.

\section{V.CONCLUSION}

The study concluded the following results:

- Social distancing has become a vital element of designing open social spaces, due to the uprising viruses and epidemics.

- The cultural and economic levels of individuals practicing activities inside the open social spaces is correlated to their level of perception to the importance of social distancing on public health. However, the social and culture levels remain a fundamental aspect of how individuals perceive the spaces and the way to practice activities inside it.

- According to the World Health Organization instructions the safe social distancing range $(1: 2 \mathrm{~m})$. The safest option is 2 meters or more, so the safe circle around each person should be at least about 3.14 meters squared.

- The presence of a network of specific signs / anchor to determine the social distancing between individuals has become one of the basic elements in the design of open spaces. These signs must be strict and enforce social distancing among people while maintaining a level of flexibility for the urban designer to alter and modify the design of the open social space.

- The fixed landscape elements (trees, shrubs, water, paving materials, landform etc.) play a rule in achieving social distancing and solving urban design problems.

- Vertical anchors that are designs with technological techniques to adjust the open space area when needed; and achieve flexibility in design.

- The role of the urban designer is fundamental in redesigning the open social spaces that ensure the practice of activities without any negative impacts on users. 
- Urban designer of the future should adopt new concepts that embrace design flexibility and usage of a technology to cope with various variables.

- Architecture education should also include flexible or adaptable design concepts.

- User participation in the decision-making is considered a necessity because of its role on convincing individuals and ensuring their full commitment for the decisions taken either by the urban designer or administration.

\section{REFERENCES}

[1] Bravo, L., "Open Spaces, Public Spaces, Publics, open-Minded Places," Doi: `0.6092/issn.2036-1602/3708, 2013.

[2] Foucault, M., "The Subject and Power," by Hubert L. Dreyfus and Paul Rabinow (eds), beyond Structuralism and Hermeneutics, 2nd ed, University of Chicago Press, 1983.

[3] Foucault, M., "Of Other Spaces," Translated by Joy Miskowiec, Diacritics 16 (1): 22.DOI: $10.2307 / 464648,1986$.

[4] Hall, E.T., "The hidden Dimension," New York, NY: Doubleday, 1966.

[5] Hanson, J. \& Hillier, B., "The Architecture of Community: Some New Proposals on the Social consequences of Architectural and Planning Decisions," Architecture and Comport/Architectural Behavior (3), 1987.

[6] Hillier, B., \& Hanson, J., "The social logic of space," Cambridge, UK: Cambridge University Press, 1984.

[7] Hillier, B., "Space and Spatiality: what the built environment needs from social theory," Building Research \& Information May/Jun 2008.

[8] Hiller, B., and Vaughan, L., "The city as one thing. In The spatial syntax of urban segregation, ed. Laura Vaughan," Progress in Planning 67 (3), 2007.

[9] Jacobs, J., "The death and life of great American cities," New York: Vintage Books, 1989.

[10] Lang, J., "Urban Design, a typology of procedures and products," Sydney, Australia: University of New South Wales, 2005.

[11] Legeby, A., "Architectural Inquiries," Chalmers Tekniska Hogskola. Goteborg: Chalmers, 2008.

[12] Mohamed, H., "Interior Architectural Elements that Affect Human Psychology and Behavior," International Journal on: The Academic Research Community Publication, Cities' Identity Through Architecture and Arts (CITAA), 2017.

[13] Shuter, P., "Proxemics and Tactility in Latin America," Journal of communication, 26, 46-52, 1976.

[14] Waite, M. \&Hawker, S., "Oxford Paperback Dictionary and Theraurus 1 Edited y Maurice Waite, Sara Hawker," .3rd ed, Oxford; New York: Oxford University Press, 2009.

Basic format for books / research / article (available online):

[15] Abu-Bakar A.\& Mohamed Osman M.\& Bachok S., (March, 2012) "Community Involvement in Cultural Activities: Theories and Concepts," Conference: First International Conference on Islamic Built EnvironmentAt: Universiti Islam Bandung. Available: https://www.researchgate.net/publication/275903988_Community_Invol vement in Cultural Activities Theories and Concepts

This information was last checked as of Saturday 15th of sep., 2020

[16] Brennon A. M., (Spring, 2010), "Architecture W/O Architecture," University of the Art, Industrial Design, Available:

https://hautecontriver.wordpress.com/2010/06/06/architecture-woarchitecture/

This information was last checked as of Saturday 15th of June, 2020.

[17] Chandran, R., (February,2020) "ANALYSIS- Unequal CITIES Bear the Brunt of Deadly Disease Outbreaks." Thomson Reuters Foundation, Available: https://news.trust.org/item/20200217002430-yvuj7/

This information was last checked as of Saturday 26th of June 2020.

[18] Legeby, A., (January, 2010), "URBAN SEGREGATION AND URBAN FORM: From residential segregation to segregation in public space," Available:

https://www.researchgate.net/publication/277771240 URBAN SEGRE GATION_AND_URBAN_FORM_From residential_segregation to_se gregation_in_public_space

This information was last checked as of Saturday 26th of June 2020.

[19] Nassiri, N. \& Powell, N. \&Moore, D. (2010) "Human Interactions and Personal Space in Collaborative Vitual Environments, Springer- -Verlag London Limited link, 229-240. https://link.springer.com/article/10.1007/s10055-010-0169-3 his information was last checked as of Saturday 28th of Sep., 2020.

[20] UN-Habitat, (June, 2013) "Charter of Public Space," Available: http://www.biennalespaziopubblico.it/wpcontrnt/uploads/2013/11/CHARTER-OF-PUBLIC-SPACE june2013 pdf-.pdf.

This information was last checked as of Saturday 9th of June 2020.

[21] Watsonville California, (March 2019), "Social Distancing in Public Parks and Trails," Available: https://www.cityofwatsonville.org/1922/SocialDistancing-in-Public-Parks-and-Tr

This information was last checked as of Saturday 30th of June 2020.

[22] World Health Organization (WHO), (June, 2020), " $1 \mathrm{~m}, 1.5 \mathrm{~m}, 2 \mathrm{~m}$ - the different levels of social distancing countries are following amid Covid19," Available: https://theprint.in/theprint-essential/1m-1-5m-2m-thedifferent-levels-of-social-distancing-countries-are-following-amidcovid/449425/

This information was last checked as of Saturday 14th of June, 2020.

[23] "Social Distancing and Contact Tracing" Available:

https://www.social-distancing-contact-

tracing.com/?gclid=CjwKCAjwzvX7BRAeEiwAsXExo42Lpp1o2iAwq Ax3pO8baLXnxjnsCttvosIaUg5J4EyE3fL0ZwWXNRoCy-

YQAvD_BwE\#features

This information was last checked as of Saturday 14th of June, 2020.

\section{Title Arabic:}

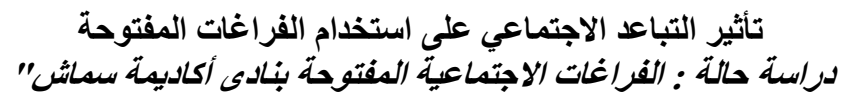

\section{Arabic Abstract:}

يمكن تعريف المناطق الحضرية على أنها فراغات خارجية تقع بين المباني التي تسمح

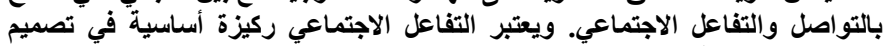
الفراغات الحضرية.

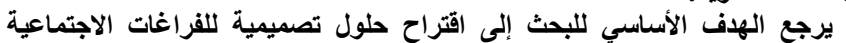

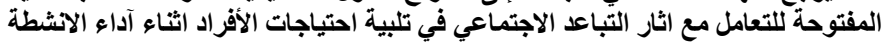

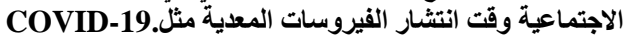

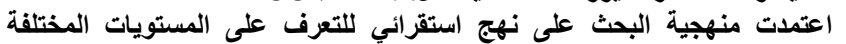

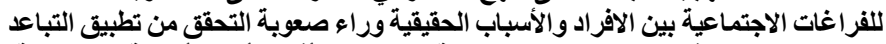

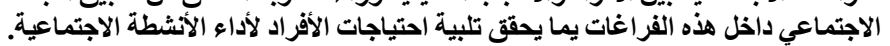

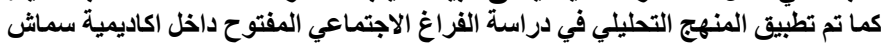

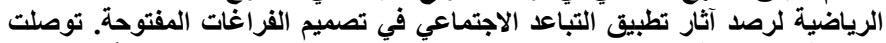

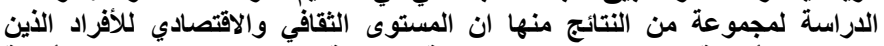

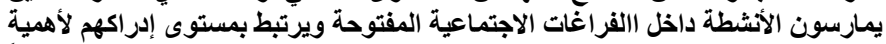

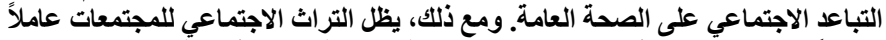

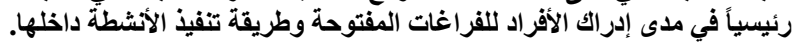

